ASIMETRIS: JURNAL PENDIDIKAN MATEMATIKA DAN SAINS

p-ISSN 2721 - 8724, e-ISSN 2722 - 0214

Website Jurnal: http://journal.umuslim.ac.id/index.php/asm/

$\begin{aligned} \text { Info Artikel: } & \text { Direvisi pada 11 Mei } 2021 \\ \text { Disubmit pada 24 April 2021 } & \text { Diterima pada 12 Mei 2021 } \\ \text { Direview pada 2 Mei 2021 } & \text { Tersedia secara daring pada 16 Mei } 2021\end{aligned}$

\title{
DIMENSI METRIK PADA GRAF CALENDULA $\left(\mathrm{Cl}_{3, n}\right)$
}

\author{
M. A. Shulhany ${ }^{1}$, Agusutrisno Agusutrisno ${ }^{2}$, Frena Fardillah ${ }^{3}$ \\ 1,2 Jurusan Teknik Sipil, Fakultas Teknik, Universitas Sultan Ageng Tirtayasa \\ 3 Jurusan Teknik Industri, Fakultas Teknik, Universitas Muhammadiyah Tangerang \\ Alamat email: ahmad.s@untirta.ac.id
}

\begin{abstract}
ABSTRAK. Semua graf $G=\left(V_{G}, E_{G}\right)$ yang dibahas pada penelitian ini merupakan graf tak-berarah, sederhana, dan berhingga. Misalkan $s$ adalah sebuah sisi graf $H$. Hasil kali sisir sisi antara graf $G$ dan graf $L$, dinotasikan dengan $G \unrhd L$, merupakan graf yang diperoleh dengan mengambil sebuah salinan $G$ dan $\left|E_{G}\right|$ buah salinan $L$ dan mencangkokkan sisi $s$ pada salinan ke- $i$ dari $L$ ke sisi ke- $i$ dari $G$. Misalkan $T=\left(t_{1}, t_{2}, \ldots, t_{k}\right)$ merupakan himpunan bagian terurut dari titik-titik pada $G$ yang anggota telah ditentukan. Representasi metrik dari $u \in V_{G}$ terhadap $T$, dan dinotasikan dengan vektor $\lambda(u \mid T)=$ $\left\{d\left(u, t_{1}\right), d\left(u, t_{2}\right), \ldots, d\left(u, t_{k}\right)\right\}$. Dimensi metrik pada $G$ adalah kardinalitas minimum dari semua himpunan $T$ pada $G$ sehingga $r\left(u_{1} \mid W\right) \neq d\left(u_{2} \mid W\right)$, dengan $u_{1} \neq u_{2}$. Pada penelitian ini, dibahas dimensi matrik untuk graf calendula $\left(\mathrm{Cl}_{3, n}\right)$.
\end{abstract}

Kata Kunci: Dimensi metrik, Representasi metrik, Graf Calendula.

ABSTRACT. All graphs $G=\left(V_{G}, E_{G}\right)$ in this study are undirected, simple, and finite graphs. Let $s$ be a edge of $H$. The edgecomb product between $G$ and $L$, denoted $G \unrhd L$, is a graph obtained by taking one copy of $G$ and $\left|E_{G}\right|$ copies of $L$ and grafting $S$ in the i-th edge of $L$ to the $i$-th edge of $G$. Let $T=\left(t_{1}, t_{2}, \ldots, t_{k}\right)$ be an ordered subset of vertices set in $G$ that have been determined. The metric representation of $u \in V_{G}$ with respect to $T$, is denoted by $\lambda(u \mid T)=\left(d\left(u, t_{1}\right), d\left(u, t_{2}\right), \ldots, d\left(u, t_{k}\right)\right)$. The metric dimension of $G$ is the minimum cardinality of all sets $T$ in $G$ such that $r\left(u_{1} \mid W\right) \neq d\left(u_{2} \mid W\right)$, which $u_{1} \neq u_{2}$. This research discusses the metric dimensions of the marigold graphs $\left(\mathrm{Cl}_{3, n}\right)$.

Keyword: Metric dimension, Metric representation, Marigold graphs

\section{PENDAHULUAN}

Graf $G=\left(V_{G}, E_{G}\right)$ merupakan pasangan terurut himpunan titik $V_{G}$ dan himpunan sisi $E_{G} \subseteq$ $\left[V_{G}\right]^{2}$. Semua graf yang dibahas pada penelitian ini merupakan graf tak-berarah, sederhana, dan berhingga. Misalkan $s$ adalah sebuah sisi graf $H$. Hasil kali sisir sisi antara graf $G$ dan graf $L$, dinotasikan dengan $G \unrhd L$, merupakan graf yang diperoleh dengan mengambil sebuah salinan $G$ dan $\left|E_{G}\right|$ buah salinan $L$ dan mencangkokkan sisi $s$ pada salinan ke- $i$ dari $L$ ke sisi ke- $i$ dari $G$ (Dafik, dkk., 2017).

Misalkan $T=\left(t_{1}, t_{2}, \ldots, t_{n}\right)$ merupakan himpunan bagian teurut dari titik-titik graf $G$ yang anggota telah ditentukan. Representasi titik $u \in$ $V_{G}$ terhadap $T$, dinotasikan dengan vektor $\lambda(u \mid T)=\left\{d\left(u, t_{1}\right), d\left(u, t_{2}\right), \ldots, d\left(u, t_{n}\right)\right\}$. Himpunan $W$ disebut himpunan pemisah pada $G$, jika untuk setiap titik $u, v$ pada $V_{G}$ dan $u \neq v$ mengakibatkan $\lambda(u \mid T) \neq \lambda(v \mid T)$ (Chartrand, dkk., 2000; Harary \& Melter, 1976).

Dimensi metrik pada $G$ adalah kardinalitas minimum dari semua himpunan pemisah pada $G$. Beberapa hasil penelitian terkait dimensi metrik sebagai berikut:

Teorema 1. (Harary \& Melter, 1976) Graf $G$ berorde $n \geq 2$ yang memiliki dimensi metrik satu jika dan hanya jika $G$ adalah graf lintasan $P_{n}$.

Teorema 2. (Harary \& Melter, 1976) Graf $G$ berorde $n \geq 2$ yang memiliki dimensi metrik $n-$ 1 jika dan hanya jika $G$ adalah graf lengkap $K_{n}$. 
Akibat 3. Jika $G$ berorde $n \geq 2$, bukan graf lengkap $K_{n}$, dan bukan graf lintasan $P_{n}$, maka

$2 \leq \operatorname{dim}(G) \leq n-2$.

Teorema 4. (Chartrand, dkk., 2000) Graf $G$ berorde $n \geq 4$ yang memiliki dimensi metrik $n-$ 2 jika dan hanya jika $G=K_{s, t}$, dengan $s, t \geq 1$ atau $G=K_{s}+\bar{K}_{t}$, atau $G=K_{s}+\left(K_{1} \cup K_{t}\right)$, dengan $s, t \geq 1$.

Teorema 5. (Chartrand, dkk., 2000) Graf $G$ berorde $n \geq 3$, berdiameter $d$, dan $f(n, d)$ adalah bilangan positif $k$ terkecil sehingga $k+$ $d^{k} \geq n$, maka

$f(n, d) \leq \operatorname{dim}(G) \leq n-d$.

Penelitian lain terkait dimensi matrik yaitu Cáceres, J., dkk (2007) meneliti hasilkali Kartesian, Díaz, dkk (2012) dan Hauptmann, dkk (2012) meneliti kompleksitas dimensi metrik, Fehr, dkk (2006) meneliti tentang digraf Cayley, Hernando, dkk (2010) meneliti dimensi metrik dilihat dari teori graf ekstermal, serta Tomescu dan Javaid (2007) meneliti graf Jahangir.

\section{METODE PENELITIAN}

Metode penelitian yang digunakan adalah metode pencarian pola dengan langkah-langkah berikut:

a. Menentukan graf yang dianalisa

b. Menentukan nama titik-titik di graf sehingga bisa diidentifikasi

c. Menentukan dugaan awal dari dimensi matrik graf

d. Membuat pembuktian awal yang berisi pembuktian batas bawah dan batas atas dari graf

e. Membuat kesimpulan dari pembuktian

\section{HASIL PENELITIAN DAN PEMBAHASAN}

Pada penelitian ini, dibahas dimensi matrik untuk graf calendula $\left(\mathrm{Cl}_{3, n}\right)$. Misalkan $n$ merupakan bilangan asli dengan $n \geq 3$.
Graf calendula berorde $3 n-3$ dinotasikan dengan $\mathrm{Cl}_{3, n}$ merupakan graf hasil kali sisir sisi dari graf lingkaran berorde 3 dan graf lingkaran berorde $n$, dinotasikan dengan $C_{3} \unrhd C_{n}$. Graf $\mathrm{Cl}_{3, n}$ merupakan graf dengan himpunan titik dan himpunan sisi masing-masing sebagai berikut:

$$
\begin{aligned}
& V\left(S f_{n}\right)=\left\{v_{i} \mid 1 \leq i \leq 3 n-3\right\} \\
& E\left(S f_{n}\right)=\left\{v_{i} v_{i+1} \mid 1 \leq i \leq 3 n-4\right\} \cup \\
& \left\{v_{1} v_{3 n-3}\right\} \cup\left\{v_{1} v_{n}\right\} \cup\left\{v_{1} v_{2 n-1}\right\} \cup \\
& \left\{v_{n} v_{2 n-1}\right\}
\end{aligned}
$$

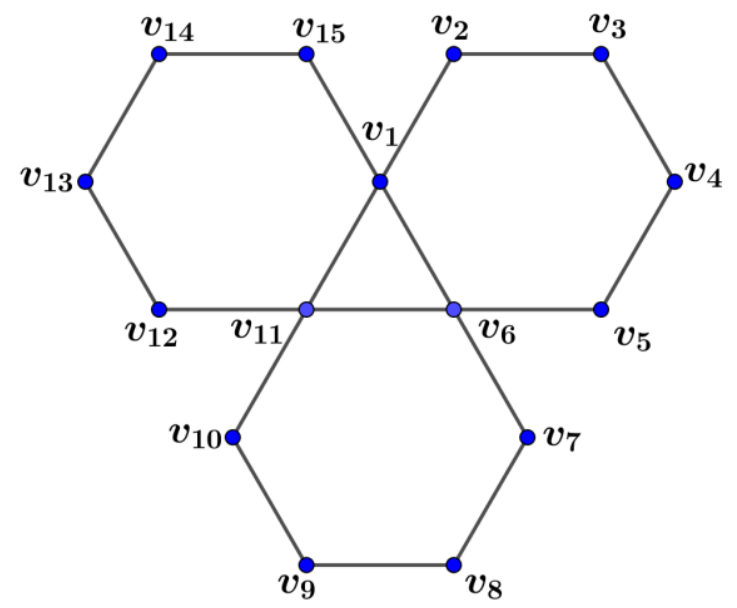

Gambar 1. llustrasi graf $S f_{n}$.

Teorema 6. Misalkan $n \geq 3$ merupakan bilangan asli. Jika $\mathrm{Cl}_{3, n}$ merupakan graf calendula berorde $3 n-3$, maka

$$
\operatorname{dim}\left(C l_{3, n}\right)=2 .
$$

Bukti.

Misalkan $n \geq 3$ merupakan bilangan asli. Graf $\mathrm{Cl}_{3, n}$ merupakan graf calendula berorde $3 n-3$. Pertama, akan ditunjukkan bahwa $\operatorname{diam}\left(\mathrm{Cl}_{3, n}\right) \geq 2$. Berdasarkan Akibat 3, kita peroleh $\operatorname{diam}\left(\mathrm{Cl}_{3, n}\right) \geq 2$. Kedua, akan ditunjukkan bahwa $\operatorname{diam}\left(\mathrm{Cl}_{3, n}\right) \leq 2$ dengan menentukan sebuah himpunan pemisah pada $\mathrm{Cl}_{3, n}$ dengan 2 titik. Pilih sebuah himpunan pemisah $T=\left\{v_{\left[\frac{n}{2}\right]}, v_{\left[\frac{3 n}{2}\right]}\right\}$. Representasi dari titik-titik $v_{i}$ dengan $T$ adalah 
1. $\lambda\left(v_{i} \mid T\right)=\left(\left\lceil\frac{n}{2}\right\rceil-i,\left\lceil\frac{n}{2}\right\rceil+i-1\right)$, untuk $1 \leq i \leq\left\lfloor\frac{n}{2}\right\rfloor$;

2. $\lambda\left(v_{i} \mid T\right)=\left(i-\left\lceil\frac{n}{2}\right\rceil,\left\lfloor\frac{3 n}{2}\right\rfloor-i\right)$, untuk $\left\lfloor\frac{n}{2}\right\rfloor+$ $1 \leq i \leq\left\lceil\frac{3 n}{2}\right\rceil-1$

3. $\lambda\left(v_{i} \mid T\right)=\left(\left[\frac{5 n}{2}\right\rceil-i-1, i-\left\lfloor\frac{3 n}{2}\right\rfloor\right)$, untuk $\left\lceil\frac{3 n}{2}\right\rceil \leq i \leq 2 n-1$;

4. $\lambda\left(v_{i} \mid T\right)=\left(i-\left\lfloor\frac{3 n}{2}\right\rfloor+1, i-\left\lfloor\frac{3 n}{2}\right\rfloor\right)$, untuk $2 n \leq i \leq\left\lfloor\frac{5 n}{2}\right\rfloor-2$;

5. $\lambda\left(v_{i} \mid T\right)=(n-1, n-1)$, untuk $i=$ $\left\lfloor\frac{5 n}{2}\right\rfloor-1$ dan bilangan ganjil $n \geq 3$;

6. $\lambda\left(v_{i} \mid T\right)=\left(\frac{1}{2}(7 n-5)-i, \frac{1}{2}(7 n-3)-\right.$ $i)$, untuk $\left\lfloor\frac{5 n}{2}\right\rfloor \leq i \leq 3 n-3$ dan bilangan ganjil $n \geq 3$;

7. $\lambda\left(v_{i} \mid T\right)=\left(\frac{1}{2}(7 n-6)-i, \frac{1}{2}(7 n-4)-\right.$ $i)$, untuk $\left\lfloor\frac{5 n}{2}\right\rfloor-1 \leq i \leq 3 n-3$ dan bilangan genap $n \geq 4$;

Melalui pemeriksaan secara langsung, terlihat bahwa $\lambda(u \mid T) \neq \lambda(v \mid T)$, untuk setiap pasang titik $u, v \in V_{C l_{3, n}}$, dan $u \neq v$. Sehingga, himpunan $T$ merupakan himpunan pemisah. Dari pernyataan satu didapat $\operatorname{diam}\left(\mathrm{Cl}_{3, n}\right) \geq 2$ dan pernyataan dua didapat $\operatorname{diam}\left(\mathrm{Cl}_{3, n}\right) \leq 2$, maka $\operatorname{diam}\left(\mathrm{Cl}_{3, n}\right)=2$.

\section{SIMPULAN}

Misalkan $n$ merupakan bilangan bulat positif dan $n \geq 3$. Jika $\mathrm{Cl}_{3, n}$ merupakan graf calendula berorde $3 n-3$, maka dimensi metriknya $\operatorname{dim}\left(\mathrm{Cl}_{3, n}\right)=2$.

\section{DAFTAR PUSTAKA}

Cáceres, J., Hernando, C., Mora, M., Pelayo, I. M., Puertas, M. L., Seara, C., \& Wood, D. R.
(2007). On the metric dimension of cartesian products of graphs. SIAM journal on discrete mathematics, 21(2), 423-441.

Chartrand, G., Eroh, L., Johnson, M. A., \& Oellermann, O. R. (2000). Resolvability in graphs and the metric dimension of a graph. Discrete Applied Mathematics, 105(1-3), 99-113.

Dafik, Agustin, I. H., Nurvitaningrum, A. I., \& Prihandini, R. M.. (2017). On super Hantimagicness of an edge comb product of graphs with subgraph as a terminal of its amalgamation. Journal of Physics: Conference Series, 855(1), 12010.

Díaz, J., Pottonen, O., Serna, M., \& Van Leeuwen, E. J. (2012). On the complexity of metric dimension. European Symposium on Algorithms, 419-430.

Fehr, M., Gosselin, S., \& Oellermann, O. R. (2006). The metric dimension of Cayley digraphs. Discrete mathematics, 306(1), 3141.

Harary, F., \& Melter, R. A. (1976). On the metric dimension of a graph. Ars combin, 2(191195), 1.

Hauptmann, M., Schmied, R., \& Viehmann, C. (2012). Approximation complexity of metric dimension problem. Journal of Discrete Algorithms, 14, 214-222.

Hernando, C., Mora, M., Pelayo, I. M., Seara, C., \& Wood, D. R. (2010). Extremal graph theory for metric dimension and diameter. The Electronic Journal of Combinatorics [electronic only], 17(1), Research-Paper.

Tomescu, I., \& Javaid, I. (2007). On the metric dimension of the Jahangir graph. Bulletin mathématique de la Société des Sciences Mathématiques de Roumanie, 371-376. 